\title{
Trends in arrivals and prices of onion in Ahmedabad (Gujarat) market
}

\begin{abstract}
It is believed that, with the increase in arrivals of agricultural commodity in the market, their prices come down and vice versa. For this study, the data on arrivals and prices was under taken up. For the study, the data available in monthly reports of Agricultural Produce Committee Ahmadabad market, for the period of 10 years was used, the annual compound growth rate of arrivals in case of onion (15.37) were found positive and annual compound growth rates of prices in the onion (19.48\%) were positive growth rate indicating thereby positive relationship in Arrivals and prices per annually. Seasonal indices of arrivals and prices of onion was that, arrivals were noticed highest during the month of December (16.98) followed by April and February. It means that the market was flooded with onion from December to April. The lowest indices of arrivals were noticed in the month of October (5.25). The indices of lower arrivals were from May to October. In case of price indices was noticed highest in the month of November (13.39). The higher prices indices were noticed during August to January. While lowest in May (4.07) followed by April and June.
\end{abstract}

KEY WORDS : APMC, Arrivals, Prices, Compound Growth Rate, Seasonal indices

How to cite this paper : Daundkar, K.S. and Bairagi, S.K. (2015). Trends in arrivals and prices of onion in Ahmedabad (Gujarat) market. Internat. J. Com. \& Bus. Manage, 8(1) : 117-119. INDIA

Authors' affiliations:

S.K. BAIRAGI, K.K. Wagh, College of Agriculture, NASHIK (M.S.) INDIA 